\title{
F2-isoprostanes and F4-neuroprostanes as markers of intracranial aneurysm development
}

\author{
Anna Syta-Krzyżanowska ${ }^{1, A-D, F}$, Iwona Jarocka-Karpowicz ${ }^{2, C}$, Jan Kochanowicz ${ }^{1, A, E, F}$, Grzegorz Turek 3,B, \\ Robert Rutkowski, ${ }^{3, B}$, Krzysztof Gorbacz ${ }^{3, B}$, Zenon Mariak ${ }^{3, A, E}$, Elżbieta Skrzydlewska ${ }^{2, C-F}$ \\ ${ }^{1}$ Department of Invasive Neurology, Medical University of Bialystok, Poland \\ ${ }^{2}$ Department of Analytical Chemistry, Medical University of Bialystok, Poland \\ ${ }^{3}$ Department of Neurosurgery, Medical University of Bialystok, Poland \\ A - research concept and design; $\mathrm{B}$ - collection and/or assembly of data; $\mathrm{C}$ - data analysis and interpretation; \\ $D$ - writing the article; $E$ - critical revision of the article; $F$ - final approval of the article
}

\section{Address for correspondence}

Anna Syta-Krzyżanowska

E-mail:annasyta@op.pl

Funding sources

None declared

Conflict of interest

None declared

Received on 0ctober 9, 2016

Reviewed on November 29, 2016

Accepted on January 24, 2017

\begin{abstract}
Background. Intracranial aneurysms are common, occurring in about 1-2\% of the population. Saccular aneurysm is a pouch-like pathological dilatation of an intracranial artery that develops when the cerebral artery wall becomes too weak to resist hemodynamic pressure and distends.

Objectives. The aim of this study was to determine whether the development of intracranial aneurysms and subarachnoid hemorrhage (SAH) affects neuronal phospholipid metabolism, and what influence different invasive treatments have on brain free radical phospholipid metabolism.
\end{abstract}

Material and methods. The level of polyunsaturated fatty acid (PUFA) cyclization products - F2-isoprostanes and F4-neuroprostanes - was examined using liquid chromatography - mass spectrometry (LC-MS) in the plasma of patients with brain aneurysm and resulting subarachnoid hemorrhage.

Results. It was revealed that an aneurysm leads to the enhancement of lipid peroxidation with a significant increase in plasma F2-isoprostanes and F4-neuroprostanes (more than 3-fold and 11-fold, respectively) in comparison to healthy subjects. The rupture of an aneurysm results in hemorrhage and an additional increase in examined prostaglandin derivatives. The embolization and clipping of aneurysms contribute to a gradual restoration of metabolic homeostasis in brain cells, which is visible in the decrease in PUFA cyclization products.

Conclusions. The results indicate that aneurysm development is associated with enhanced inflammation and oxidative stress, factors which favor lipid peroxidation, particularly in neurons, whose membranes are rich in docosahexaenoic acid, a precursor of F4-neuroprostanes.

Key words: isoprostanes, neuroprostanes, aneurysm, subarachnoid hemorrhage

DOI

$10.17219 /$ acem/68634

\section{Copyright}

Copyright by Author(s)

This is an article distributed under the terms of the

Creative Commons Attribution Non-Commercial License

(http://creativecommons.org/licenses/by-nc-nd/4.0/) 


\section{Introduction}

Intracranial aneurysms are common, occurring in about $1-2 \%$ of the population. A saccular aneurysm is a pouch-like pathological dilatation of an intracranial artery that develops when the cerebral artery wall becomes too weak to resist hemodynamic pressure and distends. Unfortunately, the majority of them do not give characteristic symptoms, while vascular diagnostics is recommended only for patients with a family history of aneurysm or subarachnoid hemorrhage $(\mathrm{SAH})$. Some intracranial aneurysms remain stable over time, but in others, mural cells die, the matrix degenerates, and eventually the wall ruptures, causing a life-threatening hemorrhage. Subarachnoid hemorrhage requires urgent diagnosis and treatment due to the high mortality and younger age of onset compared to other cardiovascular diseases. It is particularly important to prevent systemic and cerebral complications, which significantly worsen the prognosis and are associated with the occurrence of new neurological deficits, leading to disability in patients. The most favorable situation would be to diagnose and embolize or clip an aneurysm before SAH. The main problem is the lack of easily detectable, fast-emerging markers in the blood, imaging complications in the course of SAH.

The exact pathogenesis of cerebral aneurysms is not completely known, but it was shown that inflammatory and immunological mechanisms play a dominant role, and that the modifiable risk factors include smoking and high blood pressure. ${ }^{1}$ Inflammation in connection with hypertension leads to disturbances in reduction-oxidation (redox) homeostasis in the arterial wall. ${ }^{2}$ In such a situation, increased reactive oxygen species (ROS) generation results in oxidative modifications of lipids, proteins and DNA. ${ }^{3}$ Brain susceptibility to oxidative stress results from the consumption of large amounts of oxygen, alteration of the blood-brain barrier and bio-activation of glial cells. ${ }^{4}$ Moreover, the metabolism of the brain is characterized by the promotion of ROS due to its unique metabolic features, such as neurotransmitter oxidation. ${ }^{5}$ Some glial cells and macrophages can produce the superoxide anion $\left(\mathrm{O}_{2}^{-}\right)$, nitric oxide (NO) and hydrogen peroxide $\left(\mathrm{H}_{2} \mathrm{O}_{2}\right)$ indirectly through the cytokine activation. ${ }^{6}$ Additionally, some brain regions have a high concentration of non-heme iron ions that can catalyze reactive hydroxyl radical formation from hydrogen peroxide. ${ }^{7}$ In contrast to the easy triggering of ROS production in the brain, antioxidant defense is rather modest. ${ }^{8}$ In particular, the levels of catalase and glutathione peroxidase, enzymes which participate in phospholipid protection, are low in most brain regions and in cerebrospinal fluid (CSF). ${ }^{9}$ Therefore, oxidative damage to membrane phospholipids can easily occur in the central nervous system. Brain cells are susceptible to ROS action because of their high phospholipid polyunsaturated fatty acid content, primarily arachidonic acid (AA) and docosahexaenoic acid (DHA).${ }^{10}$ ROS may participate in non-specific lipid peroxidation that proceeds through chain reactions for lipid radicals, which react with oxygen to form a wide variety of products depending on the substrate oxidized. Cyclization and fragmentation are the main fatty acid transformations during free radical reactions. ${ }^{11}$

The main products of polyunsaturated fatty acid (PUFA) cyclization are prostaglandin derivatives, primarily F2-isoprostanes and F4-neuroprostanes, while fragmentation leads mainly to small-molecule unsaturated aldehydes. F2-isoprostanes are formed in all types of brain cells, mainly during the process of peroxidation of AA, while F4-neuroprostanes are derived from DHA, which is a main component of neuron phospholipids. ${ }^{12}$ Both are generated in vivo independently of cyclooxygenases, primarily by free radical-induced peroxidation, and they are more stable than reactive aldehydes. ${ }^{13}$ In addition, the products of cyclization have been found to exert potent biological actions, and hence may become mediators of diseases. ${ }^{14}$ Therefore, their measurement is currently recognized as the most accurate method of assessing oxidative injury in vivo. It has been shown that the concentration of F2-isoprostanes and F4-neuroprostanes is increased in a number of human brain diseases. ${ }^{15}$

The pathogenesis of cerebral aneurysms is not fully understood, and we lack fast and cheap diagnostic tests for them. These facts justify the search for indicators which could also help to assess the metabolic consequences of aneurysms and the results of specific medical treatment. Therefore, in this study we examined the levels of the products of PUFA cyclization in the plasma of patients with aneurysmal SAH in order to determine whether and how the development of a cerebral aneurysm, with or without $\mathrm{SAH}$, affects the neuronal metabolism of phospholipids. The influence of different invasive treatments on brain free radical phospholipid metabolism was also checked.

\section{Material and methods}

The plasma samples used in this study were collected from a group of 66 patients, including 35 women at a mean age of 54 years (range: $29-84$ years) and 31 men at a mean age of 53 years (range: $38-66$ years). Aneurysm was diagnosed in 33 patients (11 women and 22 men) at a mean age of 53 years (range: 29-69 years) and subarachnoid hemorrhage caused by the rupture of aneurysm was diagnosed in 33 patients (24 female and 9 men) at a mean age of 54 years (range: $31-84$ years). Hemorrhage was diagnosed by brain computed tomography $(\mathrm{CT})$ and aneurysm was diagnosed by angio-CT and angiography. SAH patients were evaluated at admission according to the Glasgow Coma Scale (GCS), the Hunt-Hess scale and World Federation of Neurosurgeons Scale (WFNS), which define neurological condition in relation to the size of hemorrhage. ${ }^{16-18}$ The size of hemorrhage and cerebral edema in CT was rated on the Fisher scale. ${ }^{19}$ The patient's medical history takes into account 
information which could affect the marked parameters, such as chronic diseases, drugs used in the past month, smoking, and alcohol use. The routine tests included electrocardiography (ECG) and basic blood diagnostic tests.

The control group consisted of 66 healthy subjects 35 women and 31 men, average age 54 years (range: $27-$ -79 years) (Table 1 ). All the participants were matched for sex, age, diagnosis, and blood test results. The results of the parameters of healthy subjects and patients from all groups are outlined in Table 1. The exclusion criteria were as follows: pregnancy, lack of written consent or recent treatment with certain medications, including non-steroidal antiinflammatory drugs, steroids and oral contraceptives.

The study commenced after obtaining approval from the Local Bioethics Committee at the Medical University of Bialystok (Poland), and written informed consent was obtained from all patients.

\section{Samples and laboratory measurements}

Blood samples were drawn by venipuncture and collected into heparinized and non-heparinized tubes. Samples were centrifuged at $2000 \times \mathrm{g}$, at $4^{\circ} \mathrm{C}$ for $20 \mathrm{~min}$ to obtain plasma and serum. An antioxidant, butylhydroxytoluene (BHT), was added to the plasma samples before storing them to prevent oxidation. Samples were stored at $-80^{\circ} \mathrm{C}$ until analyzed.

The serum samples were used to take laboratory measurements, including morphology, electrolyte and creatinine levels, and glucose and coagulation panels.

\section{Biochemical assays}

Total F2-isoprostane and F4-neuroprostane levels were quantified using the modified liquid chromatographymass spectrometry (LC-MS) (Agilent, Santa Clara, USA)

Table 1. Results of blood laboratory tests of healthy subjects and patients with aneurysm and SAH

\begin{tabular}{|c|c|c|c|}
\hline Parameters & $\begin{array}{c}\text { Healthy } \\
\text { subjects } \\
n=66\end{array}$ & $\begin{array}{c}\text { Aneurysm } \\
\text { patients } \\
n=33\end{array}$ & $\begin{array}{c}\mathrm{SAH} \\
\text { patients } \\
\mathrm{n}=33\end{array}$ \\
\hline WBC $\left[10^{3} / \mathrm{mm}^{3}\right]$ & $5.27 \pm 1.16$ & $8.60 \pm 3.6$ & $11.34 \pm 3.77$ \\
\hline $\mathrm{RBC}\left[10^{6} / \mu \mathrm{L}\right]$ & $4.15 \pm 0.31$ & $4.30 \pm 0.39$ & $4.08 \pm 0.56$ \\
\hline PLT $\left[\times 100000 / \mathrm{mm}^{3}\right]$ & $174 \pm 47$ & $270 \pm 80$ & $205 \pm 60$ \\
\hline Sex (male : female) & $31: 35$ & $22: 11$ & $9: 24$ \\
\hline Age ( $<50$ years : $>50$ years) & $25: 41$ & $11: 22$ & $13: 20$ \\
\hline Chronic diseases $(-:+)$ & - & $9: 24$ & $13: 20$ \\
\hline Smoking $(-:+)$ & - & $21: 9$ & $12: 13$ \\
\hline $\begin{array}{l}\text { Number of aneurysms } \\
(1:>1)\end{array}$ & - & $21: 12$ & $24: 9$ \\
\hline $\begin{array}{l}\text { Size of aneurysm } \\
(<10 \mathrm{~mm}:>10 \mathrm{~mm})\end{array}$ & - & $27: 5$ & $27: 7$ \\
\hline Embolization : clipping & - & - & 19:14 \\
\hline
\end{tabular}

WBC - white blood cells; RBC - red blood cells; PLT - blood platelets; $\mathrm{SAH}$ - subarachnoid hemorrhage. methods of Coolen and Fam, respectively, which have been described in detail. ${ }^{13,20,21}$ In short, F2-isoprostanes and F4-neuroprostanes were isolated using the solid phase extraction (SPE) method, after an alkaline hydrolysis step. All analyses were performed using an Agilent 1290 ultra-performance liquid chromatography (UPLC) system interfaced with an Agilent 6460 triple quadrupole mass spectrometer with electrospray ionization source (ESI) (Agilent). The separation was performed using a reverse phase C18 column and linear gradient with water ( $\mathrm{pH}$ 5.7) and acetonitrile (Sigma-Aldrich, Darmstadt, Germany). As an internal standard, 8 -isoPGF $2 \alpha-\mathrm{d} 4$ (Cayman Chemical, Ann Arbor, USA) was used. F2-isoprostanes were analyzed in negative ion mode using multiple reaction monitoring (MRM). The plasma 8-isoPGF2 was determined as total 8-isoPGF2 containing free and esterified 8-isoPGF2. The limit of detection (LOD) was $30 \mathrm{pg} / \mathrm{mL}$, at a signal-to-noise ratio of 3. The limit of quantitation (LoQ) for the standard F2-isoprostane was $60 \mathrm{pg} / \mathrm{mL}$, at a signal-to-noise ratio of 10 . The precision of LoQ was $8.25 \%$ (coefficient of variation - CV). The linear dynamic range was 60-6000 pg/mL. F4-neuroprostanes were analyzed by selected ion monitoring (SIM) in the $\mathrm{m} / \mathrm{z} 357$, as a series of peaks that have molecular masses and retention times expected for F4-neuroprostanes generated from the oxidation of DHA (Sigma-Aldrich) in vitro.

\section{Statistical analysis}

Data pertaining to continuous variables were expressed as mean \pm SD. The $X^{2}$ test was used for testing hypotheses pertaining to categorical variables. The normal distribution of quantitative data was verified using the KolmogorovSmirnov test, with corrections performed by the Lilliefors test and the Shapiro-Wilk test. The significance of differences between the groups was tested with the Mann-Whitney U test and the Kruskal-Wallis test. For the comparison of dependent variables, the Friedman test was used with the adjusted Conover post hoc test. A p-value of $<0.05$ was considered statistically significant. All statistical analyses were performed using Stata/IC v. 13.0 (StataCorp, College Station, USA).

\section{Results}

The results obtained in this study seem to indicate that aneurysm development leads to a significant increase in the plasma level of lipid peroxidation products, such as F2-isoprostanes and F4-neuroprostanes (more than 2 -fold and 8-fold, respectively). The rupture of an aneurysm additionally increases the level of these parameters in comparison to healthy subjects (Table 2).

Mean concentrations of F2-isoprostanes in patients with an unruptured aneurysm amounted to $235 \%$ of that found in the control group and to $264 \%$ of that in patients with 
Table 2. The plasma F2-isoprostane and F4-neuroprostane levels

\begin{tabular}{|c|c|c|c|c|c|c|}
\hline \multirow{2}{*}{ Parameters } & \multicolumn{3}{|c|}{ F2-isoprostanes [pg/mL] } & \multicolumn{3}{|c|}{ F4-neuroprostanes [pg/mL] } \\
\hline & healthy subjects & aneurysm & SAH & healthy subjects & aneurysm & $\mathrm{SAH}$ \\
\hline Plasma level & $\begin{array}{l}\text { a) } 470 \pm 126 \\
(260-790) \\
\text { b) } 442 \pm 119 \\
(240-820)\end{array}$ & $\begin{array}{c}991 \pm 617^{a} \\
(255-2526)\end{array}$ & $\begin{array}{c}1079 \pm 654 b^{b} \\
(186-2830)\end{array}$ & $\begin{array}{c}\text { a) } 694 \pm 215 \\
(390-1110) \\
\text { b) } 660 \pm 194 \\
(360-1010)\end{array}$ & $\begin{array}{c}5758 \pm 2439 \\
(1621-13097)\end{array}$ & $\begin{array}{c}6220 \pm 3869 \\
(1814-22417)\end{array}$ \\
\hline$<50$ years old & $\begin{array}{c}255 \\
(152-432)\end{array}$ & $\begin{array}{c}718 \\
(255-1769)\end{array}$ & $\begin{array}{c}1399^{*} \\
(303-2830)\end{array}$ & $\begin{array}{c}493 \\
(229-849)\end{array}$ & $\begin{array}{c}5852 \\
(1621-8636)\end{array}$ & $\begin{array}{c}5978 \\
(1814-22417)\end{array}$ \\
\hline$>50$ years old & $\begin{array}{c}332 \\
(232-516)\end{array}$ & $\begin{array}{c}1015 \\
(366-2526)\end{array}$ & $\begin{array}{c}696^{*} \\
(186-1774)\end{array}$ & $\begin{array}{c}476 \\
(278-723)\end{array}$ & $\begin{array}{c}6066 \\
(2985-13097)\end{array}$ & $\begin{array}{c}5387 \\
(2082-9628)\end{array}$ \\
\hline Male & $\begin{array}{c}282 \\
(152-516)\end{array}$ & $\begin{array}{c}644 \\
(366-2526)\end{array}$ & $\begin{array}{c}1256 \\
(186-2212)\end{array}$ & $\begin{array}{c}465 \\
(230-849)\end{array}$ & $\begin{array}{c}5873 \\
(3122-13097)\end{array}$ & $\begin{array}{c}4603 \\
(1814-7572)\end{array}$ \\
\hline Female & $\begin{array}{c}335 \\
(172-389)\end{array}$ & $\begin{array}{c}754 \\
(255-2013)\end{array}$ & $\begin{array}{c}858 \\
(283-2830)\end{array}$ & $\begin{array}{c}610 \\
(282-787)\end{array}$ & $\begin{array}{c}6083 \\
(1621-9606)\end{array}$ & $\begin{array}{c}5744 \\
(2082-22417)\end{array}$ \\
\hline$>1$ aneurysm & - & $\begin{array}{c}758 \\
(366-2526)\end{array}$ & $\begin{array}{c}971 \\
(303-1901)\end{array}$ & - & $\begin{array}{c}5750 \\
(1621-13097)\end{array}$ & $\begin{array}{c}9810^{*} \\
(5934-13153)\end{array}$ \\
\hline $\begin{array}{l}\text { Aneurysm size } \\
<10 \mathrm{~mm}\end{array}$ & - & $\begin{array}{c}1202 \\
(433-1856)\end{array}$ & $\begin{array}{c}1180 * \\
(186-2830)\end{array}$ & - & $\begin{array}{c}6606 \\
(3568-13097)\end{array}$ & $\begin{array}{c}5387 \\
(1814-22417)\end{array}$ \\
\hline $\begin{array}{l}\text { Aneurysm size } \\
>10 \mathrm{~mm}\end{array}$ & - & $\begin{array}{c}721 \\
(260-2526)\end{array}$ & $\begin{array}{c}293^{*} \\
(274-1915)\end{array}$ & - & $\begin{array}{c}5852 \\
(1621-9234)\end{array}$ & $\begin{array}{c}6179 \\
(3145-13153)\end{array}$ \\
\hline
\end{tabular}

a the control group for aneurysm; ${ }^{b}$ the control group for $\mathrm{SAH} ;{ }^{*}$ statistical difference.

subarachnoid hemorrhage. The difference in isoprostane concentration between patients with a ruptured and unruptured aneurysm was not as substantial, reaching merely $9 \%$. The plasma concentration of F4-neuroprostanes was significantly higher than that of F2, reaching $1027 \%$ in the aneurysm group and $1141 \%$ in the aneurysm and SAH group as compared to healthy subjects. When comparing the patients with unruptured and ruptured aneurysms, the values for patients with SAH were found to be $10 \%$ higher.

The iso- and neuroprostane plasma levels with additional information concerning the patients are listed in Table 2.

Due to the mean age of 50.08 years in all treated patients, a concentration of oxidative stress parameters was rated above and below 50 years. Table 2 shows the values of F2isoprostane and F4-neuroprostane levels in the age groups; the marked p-value for the healthy and aneurysm patients is not statistically significant, whereas in the group with hemorrhage, the concentration of F2-isoprostanes is significantly higher, with $\mathrm{p}<0.05$. The concentration of F2isoprostanes and F4-neuroprostanes were also compared in diversity by gender, described using the Mann-Whitney $\mathrm{U}$ test, but there was no statistically significant difference between men and women.

The size of an intracranial aneurysm had a statistically significant impact on plasma F2-isoprostanes at the time of hemorrhage, with $\mathrm{p}<0.05$. The results are shown in Table 2. The values of F4-neuroprostanes are higher for several intracranial aneurysms at admission and discharge.

A number of factors have an effect on oxidative stress, including chronic diseases, inflammation, smoking, and alcohol abuse. The influence of the above-mentioned factors on the value of F2-isoprostanes and F4-neuroprostanes was taken into consideration in the group of patients with SAH at the time of onset and at discharge. These parameters are shown in Table 3 . The group of alcohol-abusing patients was too small to carry out credible statistical analysis.

Each SAH patient was examined neurologically on admission to the Department of Neurosurgery (Clinical Hospital of Medical University of Bialystok, Poland), after their medical history was taken. Neck stiffness was observed in all patients and Kernig's sign was present in $64 \%$ of patients. We observed the following focal symptoms in 5 patients: hemiparesis, blurred vision, and speech impairment in the form of motor and mixed aphasia. The remaining patients presented only neck stiffness. The Hunt-Hess scale illustrates neurological condition in relation to the degree of impaired consciousness and changes in the brain CT scans. There was no statistically significant difference between these groups of patients, but the values of measured parameters decreased faster in patients with less neurological deficit.

Dependence of the iso- and neuroprostane concentration was assessed in relation to the WFNS. The clinical grading system is based on the GCS and on the presence of neurological symptoms. Grade I without motor deficit was observed in 24 people and was compared with patients in the other stages. We observed 2 patients in both grade II, with impaired orientation, and grade IV with motor deficit and significant impairment of consciousness. The results did not differ in these groups. Indeed, a statistical decrease was recorded during hospitalization. 
The Fisher scale is based on changes observed in brain CT scans performed for each patient on hospital admission. Grades 1 or 2 were found in 11 patients with a small amount of blood in the subarachnoid space. Grade 3 was found in 4 of them with hematoma in the subarachnoid space and in 18 patients with blood perforation into the ventricular system. There was a statistically significant difference in the concentration of F4-neuroprostanes at discharge between grades 2 and 3 on the Fisher scale, with $\mathrm{p}<0.05$.

Edema was observed in brain CT scans of 20 patients with subarachnoid hemorrhage. The analyzed parameters of oxidative stress were higher in the case of F4-neuroprostanes, but showed no statistical significance, with $\mathrm{p}>0.05$. On the other hand, intracerebral hematoma appeared in 6 patients; its presence did not affect plasma isoprostanes ( $\mathrm{p}=0.4975)$ or neuroprostanes $(\mathrm{p}=0.3559)$ in the blood. However, for patients without intracerebral hematoma, the value of the F4-neuroprostanes decreased significantly faster, visualizing higher expiration of oxidative stress, with $\mathrm{p}<0.05$.

Each patient hospitalized in the course of SAH was monitored by transcranial Doppler (TCD) for vasospasm. This complication occurred in $17 \%$ of patients; the evaluated iso- and neuroprostane levels are shown in Table 3. The average values of F4-neuroprostanes were higher at admission and discharge in the case of vasospasm, falling significantly during hospitalization only in patients without vasospasm.

Aneurysms were embolized in 19 patients; in the remaining 14 patients, aneurysms were successfully clipped after angiography in all cases. Additionally, stress parameters were measured for 23 patients after the surgical procedure. The mean concentration of F2-isoprostanes increased by $7.8 \%$ on average after aneurysm treatment, and at discharge it decreased by $30.9 \%$, representing $25.5 \%$ below baseline. Comparing the types of surgical intervention, lower values of isoprostanes can be observed after embolization, with a direct decrease during hospitalization (Fig. 1).

The mean values of neuroprostanes are several times higher, falling gradually after onset (Fig. 2).

This decrease since hospital admission is more significant in the case of embolized aneurysms. The distribution of concentration for clipping is also connected with an initial postoperative increase, as in the case of F2-isoprostanes.
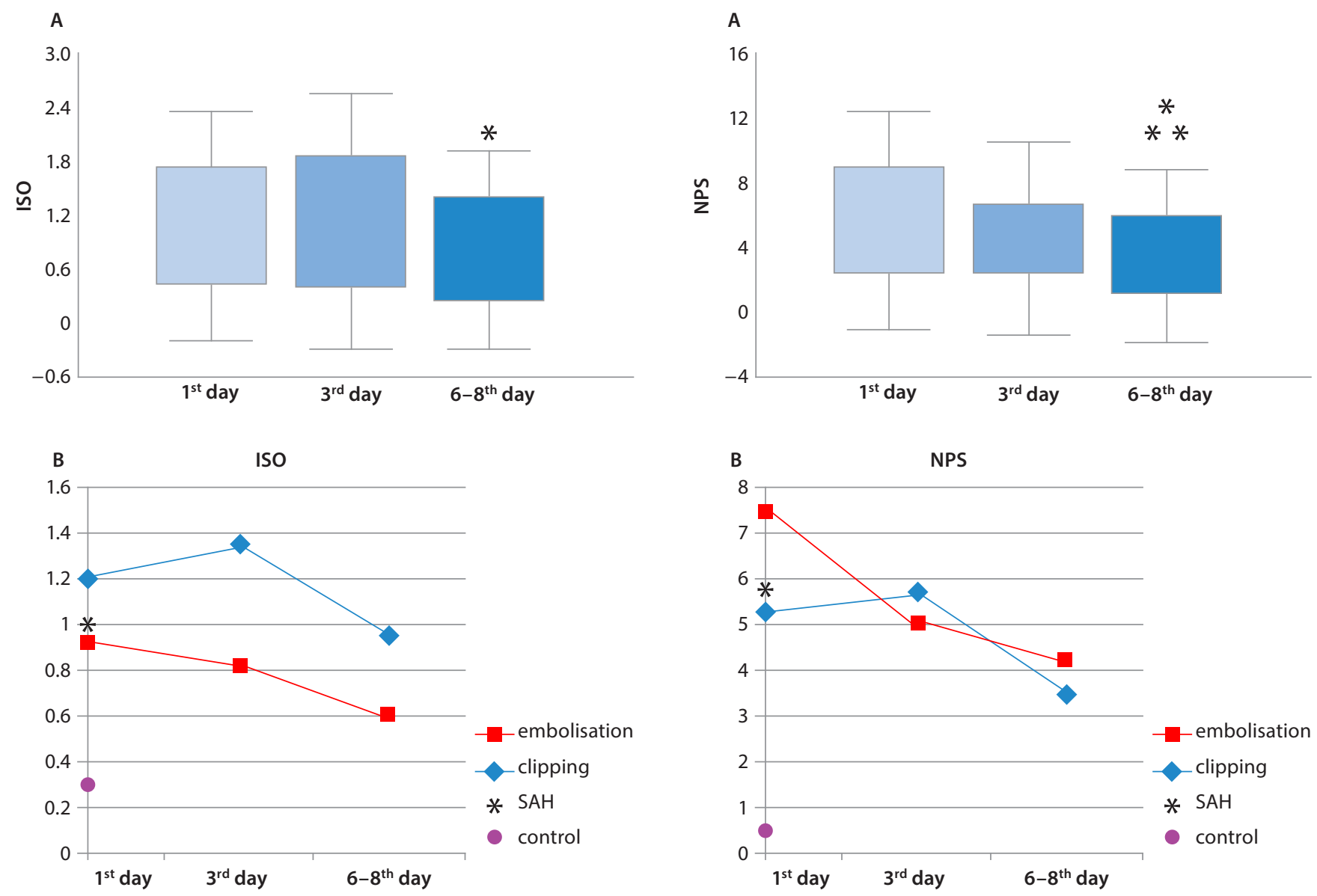

Fig. 1. The F2-isoprostanes (ISO) in patients with SAH before and after treatment

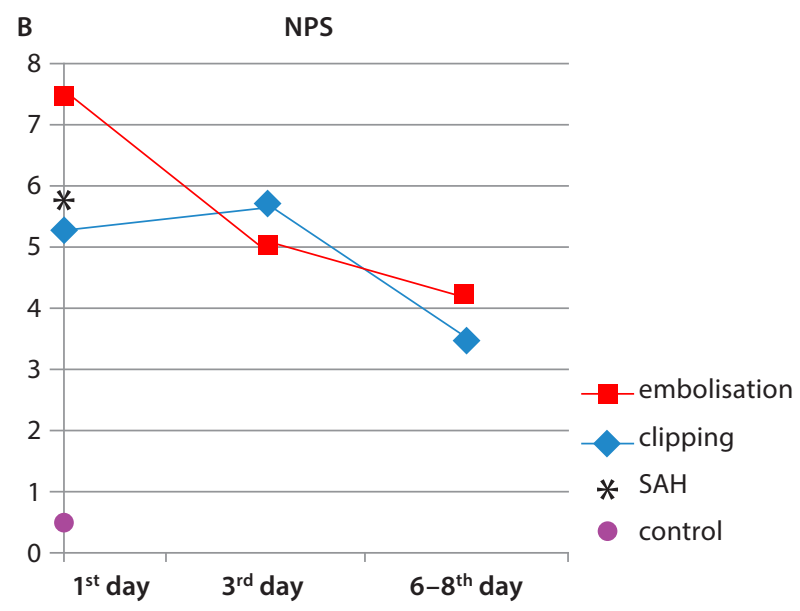

Fig. 2. The F4-neuroprostanes (NPS) in patients with SAH before and after treatment 
Table 3. The plasma F2-isoprostane and F4-neuroprostane levels in SAH patients before and after treatment

\begin{tabular}{|c|c|c|c|c|c|c|}
\hline \multirow{2}{*}{\multicolumn{2}{|c|}{ Parameters }} & \multirow{3}{*}{$\begin{array}{l}n \\
13\end{array}$} & \multicolumn{2}{|c|}{ F2-isoprostanes [pg/mL] } & \multicolumn{2}{|c|}{ F4-neuroprostanes [pg/mL] } \\
\hline & & & $1^{\text {st }}$ day & $6-8^{\text {th }}$ day & $1^{\text {st }}$ day & $6-8^{\text {th }}$ day \\
\hline \multirow{2}{*}{ Chronic disease } & - & & $\begin{array}{c}962 \pm 759 \\
(274-2830)\end{array}$ & $\begin{array}{c}625 \pm 410 \\
(116-1454)\end{array}$ & $\begin{array}{c}5834 \pm 3035 \\
(1814-13153)\end{array}$ & $\begin{array}{l}3542 \pm 2425 \\
(1433-9518)\end{array}$ \\
\hline & + & 20 & $\begin{array}{c}961 \pm 595 \\
(186-2212)\end{array}$ & $\begin{array}{c}690 \pm 634 \\
(171-2867)\end{array}$ & $\begin{array}{c}5390 \pm 4656 \\
(1953-22417)\end{array}$ & $\begin{array}{c}3265 \pm 1690^{*} \\
(864-6112)\end{array}$ \\
\hline \multirow{2}{*}{ Smoking } & - & 12 & $\begin{array}{l}1084 \pm 670 \\
(283-2830)\end{array}$ & $\begin{array}{c}690 \pm 751 \\
(180-2867)\end{array}$ & $\begin{array}{c}5610 \pm 5441 \\
(2082-22417)\end{array}$ & $\begin{array}{l}3110 \pm 1434 \\
(864-9520)\end{array}$ \\
\hline & + & 13 & $\begin{array}{c}803 \pm 624 \\
(186-2210) \\
\end{array}$ & $\begin{array}{c}553 \pm 438 \\
(117-1562) \\
\end{array}$ & $\begin{array}{l}5834 \pm 2427 \\
(1814-9628)\end{array}$ & $\begin{array}{l}3680 \pm 2714 \\
(1020-5740)\end{array}$ \\
\hline \multirow{2}{*}{ Kernig's sign } & - & 12 & $\begin{array}{c}858 \pm 506 \\
(274-1901)\end{array}$ & $\begin{array}{c}559 \pm 398 \\
(116-1454)\end{array}$ & $\begin{array}{c}6854 \pm 5235 \\
(3289-22417)\end{array}$ & $\begin{array}{c}4890 \pm 2304^{*} \\
(1020-9518)\end{array}$ \\
\hline & + & 21 & $\begin{array}{r}1009 \pm 719 \\
(186-2830) \\
\end{array}$ & $\begin{array}{c}680 \pm 621 \\
(171-2867) \\
\end{array}$ & $\begin{array}{l}4603 \pm 2056 \\
(1814-9984) \\
\end{array}$ & $\begin{array}{l}3112 \pm 1653^{*} \\
(864-7895)\end{array}$ \\
\hline \multirow{2}{*}{ Focal signs } & - & 28 & $\begin{array}{c}985 \pm 631 \\
(186-2830)\end{array}$ & $\begin{array}{c}652 \pm 583 \\
(116-2867)\end{array}$ & $\begin{array}{c}5611 \pm 4179 \\
(1814-22417)\end{array}$ & $\begin{array}{l}3258 \pm 2139 * \\
(1020-9518)\end{array}$ \\
\hline & + & 5 & $\begin{array}{c}630 \pm 852 \\
(404-2212)\end{array}$ & $\begin{array}{c}553 \pm 412 \\
(389-1374)\end{array}$ & $\begin{array}{c}5122 \pm 3252 \\
(1953-9984)\end{array}$ & $\begin{array}{l}3542 \pm 1738 \\
(864-5740)\end{array}$ \\
\hline \multirow{2}{*}{ Hunt-Hess scale } & 1 & 19 & $\begin{array}{l}1192 \pm 473 \\
(283-1901)\end{array}$ & $\begin{array}{l}755 \pm 421^{*} \\
(116-1562)\end{array}$ & $\begin{array}{c}5654 \pm 4681 \\
(1814-22417)\end{array}$ & $\begin{array}{l}3261 \pm 1745^{*} \\
(1020-7233)\end{array}$ \\
\hline & $2-4$ & 14 & $\begin{array}{c}627 \pm 855 \\
(186-2830)\end{array}$ & $\begin{array}{c}542 \pm 717 \\
(171-2867) \\
\end{array}$ & $\begin{array}{c}5167 \pm 2456 \\
(1953-9984)\end{array}$ & $\begin{array}{c}3480 \pm 2492 \\
(864-9518)\end{array}$ \\
\hline \multirow{2}{*}{ WFNS } & 1 & 24 & $\begin{array}{c}937 \pm 637 \\
(186-2830)\end{array}$ & $\begin{array}{c}625 \pm 444 \\
(116-1562)\end{array}$ & $\begin{array}{c}5654 \pm 4376 \\
(1814-22417)\end{array}$ & $\begin{array}{l}3680 \pm 2210^{*} \\
(1020-9518)\end{array}$ \\
\hline & $2-4$ & 9 & $\begin{array}{c}825 \pm 724 \\
(404-1965)\end{array}$ & $\begin{array}{c}934 \pm 788 \\
(171-2867)\end{array}$ & $\begin{array}{l}5562 \pm 2647 \\
(2082-9984)\end{array}$ & $\begin{array}{l}3337 \pm 1283^{*} \\
(1206-4601)\end{array}$ \\
\hline \multirow{2}{*}{ Fisher Scale } & $1-2$ & 11 & $\begin{array}{c}889 \pm 579 \\
(186-1897)\end{array}$ & $\begin{array}{c}626 \pm 462 \\
(116-1562)\end{array}$ & $\begin{array}{c}5086 \pm 3417 \\
(1814-13153)\end{array}$ & $\begin{array}{l}4125 \pm 1880 \\
(1433-7233)\end{array}$ \\
\hline & $3-4$ & 22 & $\begin{array}{c}985 \pm 691 \\
(274-2830)\end{array}$ & $\begin{array}{c}788 \pm 602 \\
(171-2867)\end{array}$ & $\begin{array}{c}5654 \pm 4324 \\
(1953-22417)\end{array}$ & $\begin{array}{c}3340 \pm 2135^{*} \\
(864-9518)\end{array}$ \\
\hline \multirow{2}{*}{ Brain edema } & - & 12 & $\begin{array}{l}1009 \pm 529 \\
(186-1897)\end{array}$ & $\begin{array}{c}625 \pm 718 \\
(310-2867)\end{array}$ & $\begin{array}{l}5086 \pm 1892 \\
(2082-8715)\end{array}$ & $\begin{array}{l}3256 \pm 1448 \\
(1664-6112)\end{array}$ \\
\hline & + & 21 & $\begin{array}{c}858 \pm 723 \\
(274-2830)\end{array}$ & $\begin{array}{c}586 \pm 411 \\
(116-1454)\end{array}$ & $\begin{array}{c}5654 \pm 4752 \\
(1814-22417)\end{array}$ & $\begin{array}{r}3555 \pm 2375^{*} \\
(864-9518)\end{array}$ \\
\hline \multirow{2}{*}{ Hematoma } & - & 26 & $\begin{array}{c}1105 \pm 639 \\
(186-2830)\end{array}$ & $\begin{array}{c}866 \pm 583 \\
(116-2867)\end{array}$ & $\begin{array}{c}6477 \pm 4314 \\
(1814-22417)\end{array}$ & $\begin{array}{l}3701 \pm 1623^{*} \\
(1020-7233)\end{array}$ \\
\hline & + & 7 & $\begin{array}{c}980 \pm 752 \\
(274-2212) \\
\end{array}$ & $\begin{array}{c}571 \pm 393 \\
(171-1177) \\
\end{array}$ & $\begin{array}{c}5151 \pm 2192 \\
(1953-7572)\end{array}$ & $\begin{array}{l}3874 \pm 3414 \\
(864-9518)\end{array}$ \\
\hline \multirow{2}{*}{ Vasospasm } & - & 24 & $\begin{array}{c}1192 \pm 575 \\
(186-2212)\end{array}$ & $\begin{array}{l}717 \pm 560^{*} \\
(171-2867)\end{array}$ & $\begin{array}{c}5562 \pm 2446 \\
(1814-10290)\end{array}$ & $\begin{array}{c}3256 \pm 1853^{*} \\
(864-7895)\end{array}$ \\
\hline & + & 5 & $\begin{array}{l}449 \pm 1086 \\
(274-2830)\end{array}$ & $\begin{array}{l}310 \pm 90 * \\
(171-377)\end{array}$ & $\begin{array}{c}6854 \pm 8596 \\
(3156-22417)\end{array}$ & $\begin{array}{l}3569 \pm 2996 \\
(2101-9518)\end{array}$ \\
\hline
\end{tabular}

* statistically different; WFNS - World Federation of Neurosurgeons Scale.

\section{Discussion}

An intracranial aneurysm, usually formed at cerebral artery bifurcations, is the result of pathological changes reducing the strength and stretching of the arterial wall, and hemodynamic blood flow, to which endothelial cells are exposed. ${ }^{22,23}$ The loss of endothelium continuity and exposure to collagen leads to thrombus formation, in which blood cells get trapped. Trapped platelets release platelet growth factors that react with the receptors of muscle cells, leading to proliferation. ${ }^{24}$ Moreover, the concomitant release of vascular endothelial growth factor (VEGF) increases endothelial permeability, thus facilitating the accumulation of lipids and plasma proteins, including antibodies and complement components in the arterial wall. Neutrophils, trapped in the thrombus, are a source of proteases and other cytotoxic and pro-inflammatory compounds which increase oxidative stress and damage the intima and media. ${ }^{25}$ Therefore, it is suggested that chronic inflammation is the primary reason for arterial wall degeneration. ${ }^{1}$ An increase in macrophage, $\mathrm{T}$ cell and leukocyte infiltration in the wall produces ROS that can modify the protein 
and lipid components - extracellular as well as cellular - and in consequence, the atherosclerotic walls contain accumulated lipids. The accumulation of lipids and lowdensity lipoproteins (LDLs) in the intima of the cerebral artery walls over time leads to intimal thickening and to changes in their structure, and finally, their functions. It refers particularly to brain membrane phospholipids that contain a high content of highly PUFAs, including arachidonic acid, linoleic acid, and docosahexaenoic acid. ${ }^{26}$ When they are attacked by ROS, peroxidation products are formed with peroxides first, and consequently, an increase in lipid peroxidation is observed. ${ }^{27}$ Moreover, PUFA peroxidation is enhanced in the presence of transition metal ions, such as copper and iron ions. Iron is found throughout the brain, and damage to brain tissue releases iron ions in a form which is capable of catalyzing free radical reactions, such as hydroxyl radicals formed from hydrogen peroxide or lipid peroxidation. Unfortunately, CSF has no significant ability to bind any released iron ions, which further promotes lipid peroxidation in the central nervous system (CNS). ${ }^{28}$ A relatively stable group of lipid peroxidation products is the prostaglandin-like compound group, including F2-isoprostanes and F4-neuroprostanes, whose levels are also significantly enhanced during aneurysm development, as was shown in this study. It confirms that the non-enzymatic mechanisms of oxidation of AA esterified at the sn-2 position of different cells of cellular and lipoprotein phospholipids, and DHA esterified at the sn-2 position of neuron phospholipids play an important role in brain diseases, since F2-isoprostanes are formed mainly during the peroxidation of AA, the most abundant in all types of cells, whereas F4-neuroprostanes are derived from DHA, in which neurons are particularly rich. ${ }^{29}$ F2-isoprostanes and F4-neuroprostanes are recognized as specific markers of lipid peroxidation and are superior to other markers of oxidative damage. The elevated level of prostaglandin derivatives has been observed in a number of human CNS diseases linked to oxidative stress. ${ }^{30,31}$ The level of these compounds was also significantly increased in the plasma of patients with aneurysm, where the F2-isoprostane and F4-neuroprostane levels were approx. 3-fold and 10-fold higher than in the controls.

Further endothelial dysfunction, loss of muscle cells and the infiltration of inflammatory cells escalate inflammation and matrix degradation in the wall of the aneurysm, and lead to its rupture. ${ }^{32,33}$ This study revealed that aneurysm rupture was accompanied by an additional increase in F2isoprostanes and F4-neuroprostanes. The number of such accidents increases with age. The average age for subarachnoid hemorrhage in the literature is 60 years. In this study, the average age for SAH was 54 years and women accounted for $72 \%$ of them. Female gender was also rated in the previous meta-analyses as a risk factor of rupture. ${ }^{23}$ Another general factor influencing aneurysm rupture is smoking. Smoking patients made up half the cases in the study group, which also coincides with previous analyses, because in Europe, $45-75 \%$ of patients with ruptured aneurysms are smokers. In the general population, this incidence rate is $20-35 \%$. The factors increasing the risk of rupture are polycyclic shape and size, the most commonly ruptured aneurysms being between 6 and $15 \mathrm{~mm}$. Assessing the size, only $18 \%$ of ruptured aneurysms were larger than $10 \mathrm{~mm}$. The extravasation of blood into the subarachnoid space during aneurysm rupture causes a decrease in superoxide dismutase (SOD) activity in erythrocytes, which reduces their antioxidant ability and is conducive to increased membrane lipid peroxidation. The disintegrating erythrocytes become a source of free iron ions released from hemoglobin, which may participate in the Fenton reaction, leading to the formation of hydroxyl radicals $(\cdot \mathrm{OH})$ and an increase in cascade radical reactions. ${ }^{34}$ This is accompanied by the release of pro-inflammatory factors, leading to local and systemic inflammation. ${ }^{35}$ As a result of this release from a ruptured artery and the migration in the course of inflammatory leukocytes, comes the mass overproduction of free radicals and increased oxidative stress. Irritation of the arteries by the breakdown of hemoglobin products manifested by spontaneous vasospasm is particularly hazardous. ${ }^{36}$ The result might be brain tissue damage by ischemia-reperfusion or development of a delayed ischemic neurological deficit (DIND). The activated microglia and macrophages generate superoxide anion and hydrogen peroxide as well as the release of pro-inflammatory cytokines, such as IL-1, IL- 6 and TNF- $\alpha$, resulting in oxidative stress generation with subsequent lipid peroxidation. A particularly exacerbated inflammation and lipid peroxidation was observed in a study of younger patients ( $<50$ years of age), suggesting a faster accumulation of systemic inflammatory responses. In addition, we observed a higher level of F4-neuroprostanes in the case of several cerebral aneurysms. Additional symptoms consistent with focal brain injury, such as hemiparesis, blurred vision, and motor and mixed aphasia, occurred in 5-15\% of patients, much less than in the previous studies. The F2-isoprostane and F4-neuroprostane concentrations showed a greater decrease, providing for a faster stabilization of the prooxidative - antioxidative balance in asymptomatic patients with focal CNS injury, as well as in patients in the best condition according to the Hunt-Hess scale and the WFNS, based on the GCS. In our observation, the advancement of hemorrhagic and edemic changes observed in the brain in the course of SAH did not correlate with the parameters of oxidative stress in the blood, which has been observed in CSF. ${ }^{37}$

The neurosurgical treatment of SAH patients diagnosed with a ruptured aneurysm consists of clipping or coiling as less invasive techniques. Aneurysm embolization was performed in 19 patients, which accounted for $58 \%$ of patients. In the remaining 14 patients, the aneurysms were clipped after angiography. A gradual restoration of brain metabolic homeostasis by embolization and clipping is shown by a target decrease in the level of plasma F2isoprostanes and F4-neuroprostanes. 
A complication occurring in the course of SAH was vasospasm, observed in $17 \%$ of patients, imaged by TCD. This value is much lower than estimated in previous studies, which affects $67 \%$ of patients, with a focal onset of symptoms in $24-32 \%$ of patients. ${ }^{36}$ The cause may be the quick exclusion of the aneurysm from the systemic circulation and the implementation of a "triple- $\mathrm{H}$ " treatment on hospital admission. In the case of vasospasm, the F4neuroprostane level was higher with a slower decrease than in patients without this complication. In the recent publications, mortality was estimated at $30-40 \%{ }^{38}$ The above study recorded only 1 death. This fact could have been due to the center's experience in aneurysm embolization and clipping conducted in the Neurosurgical Intensive Care Unit, and the prevention of complications.

In conclusion, it was revealed that aneurysm leads to an increase in the cyclized products of PUFA peroxidation (F2-isoprostanes and F4-neuroprostanes). However, the rupture of an aneurysm results in hemorrhage and an additional increase in the examined prostaglandin derivatives. Embolization and clipping of aneurysms contribute to a gradual restoration of metabolic homeostasis in brain cells, which is visible in the decreasing level of the examined lipid peroxidation products. These parameters, F4-isoprostanes in particular, could be useful in monitoring the onset of intracranial aneurysm development and the effectiveness of therapy.

\section{References}

1. Tulamo R, Frozen J, Hernesniemi J, Niemela M. Inflammatory changes in the aneurysm wall: A review. J Neurointerv Surg. 2010;2(2):120-130.

2. Chalouhi N, Hoh BL, Hasan D. Review of cerebral aneurysm formation, growth, and rupture. Stroke. 2013;44(12):3613-3622.

3. Aoki T, Nishimura M, Kataoka H, et al. Reactive oxygen species modulate growth of cerebral aneurysms: A study using the free radical scavenger edaravone and p47phox (-/-) mice. Lab Invest. 2009;89(7):730-741.

4. Nag S, Kapadia A, Stewart DJ. Review: Molecular pathogenesis of blood-brain barrier breakdown in acute brain injury. Neuropathol Appl Neurobiol. 2011;37(1):3-23.

5. Joseph JA, Shukitt-Hale B, Casadeus G, Fisher D. Oxidative stress and inflammation in brain aging: Nutritional considerations. Neurochem Res. 2005;30(6/7):927-935.

6. Li WJ. Research progress in the mechanism of brain self-repair [in Chinese]. Zhongguo Dang Dai Er Ke Za Zhi. 2011;13(7):606-611.

7. Sadrzadeh SMH, Saffari Y. Iron and brain disorders. Am J Clin Pathol. 2004;121:64-70.

8. Shila S, Kokilavani V, Subathra M, Panneerselvam C. Brain regional responses in antioxidant system to alpha-lipoic acid in arsenic intoxicated rat. Toxicology. 2005;210(1):25-36.

9. Kerman M, Cirak B, Ozguner MF, et al. Does melatonin protect or treat brain damage from traumatic oxidative stress? Exp Brain Res. 2005;163:406-410.

10. Mazza M, Pomponi M, Janiri L, Bria P, Mazza S. Omega-3 fatty acids and antioxidants in neurological and psychiatric diseases: An overview. Prog Neuropsychopharmacol Biol Psychiatry. 2007;31(1):12-26.

11. Catala A. Five decades with polyunsaturated fatty acids: Chemical synthesis, enzymatic formation, lipid peroxidation and its biological effects. J Lipids. 2013;2013:710290.

12. Nkiki E. Biomarkers of lipid peroxidation in clinical material. Biochem Biophys Acta. 2014;1840(2):809-817.

13. Fam SS, Murphey LJ, Terry ES, et al. Formation of highly reactive A-ring and J-ring isoprostane-like compounds (A4/J4-neuroprostanes) in vivo from docosahexaenoic acid. J Biol Chem. 2002;277(39):36076-36084.
14. Miller E, Morel A, Saso L, Saluk J. Isoprostanes and neuroprostanes as biomarkers of oxidative stress in neurodegenerative diseases. Oxid Med Cell Longev. 2014;2014:572491.

15. Milne GL, Yin H, Morrow JD. Human biochemistry of the isoprostane pathway. J Biol Chem. 2008;283(23):15533-15537.

16. Teasdale G, Jennett $B$. Assessment of coma and impaired consciousness: A practical scale. Lancet. 1974;2:81-84.

17. Hunt $W E$, Hess RM. Surgical risk as related to time of intervention in the repair of intracranial aneurysms. J Neurosurg. 1968;28(1):14-20.

18. Teasdale GM, Drake CG, Hunt W, et al. A universal subarachnoid hemorrhage scale: Report of a committee of the Word Federation of Neurosurgical Societies. J Neurol Neurosurg Psych. 1988;51(11):1457.

19. Fisher CM, Kistler JP, Davis JM. Relation of cerebral vasospasm to subarachnoid hemorrhage visualized by computerized tomographic scanning. Neurosurg. 1980;6:1-9.

20. Coolen SA, van Buuren B, Duchateau G, Upritchard J, Verhagen H. Kinetics of biomarkers: Biological and technical validity of isoprostanes in plasma. Amino Acids. 2005;29(4):429-436.

21. Łuczaj W, Moniuszko A, Rusak M, Pancewicz S, Zajkowska J, Skrzydlewska E. Lipid peroxidation products as potential bioindicators of Lyme arthritis. Eur J Clin Microbiol Infect Dis. 2011;30(3):415-422.

22. Juvela S, Poussa K, Porras M. Factors affecting formation and growth of intracranial aneurysms: A long-term follow-up study. Stroke. 2001;32(2):485-491.

23. Laaksamo $E$, Tulamo $R$, Liiman $A$, et al. Oxidative stress is associated with cell death, wall degradation, and increased risk of rupture of the intracranial aneurysm wall. Neurosurgery. 2013;72(1):109-117.

24. Nurden AT. Platelets, inflammation and tissue regeneration.J Thromb Haemost. 2011;105(Suppl 1):S13-S33.

25. Frosen J, Piippo A, Paetau A, et al. Remodeling of saccular cerebral artery aneurysm wall is associated with rupture: Histological analysis of 24 unruptured and 42 ruptured cases. Stroke. 2004;35(10):2287-2293.

26. Bourre JM. Diet, brain lipids, and brain functions: Polyunsaturated fatty acids, mainly omega-3 fatty acids. In: Lajtha A, Vizi SE, eds. Handbook of Neurochemistry and Molecular Neurobiology. New York, NY: Springer US; 2009:409-441.

27. Lajtha A, ed. Handbook of Neurochemistry and Molecular Neurobiology: Neural Lipids. New York, NY: Springer US; 2010.

28. Gueraud F, Atalay M, Bresgen N, et al. Chemistry and biochemistry of lipid peroxidation products. Free Radical Res. 2010;44(10):1098-1124.

29. Halliwell B. Reactive oxygen species and the central nervous system. J Neurochem. 1992;59(5):1609-1623.

30. Montuschi P, Barnes PJ, Roberts LJ. Isoprostanes: Markers and mediators of oxidative stress. FASEB J. 2004;18(15):1791-1800.

31. Nowak JZ. Oxidative stress, polyunsaturated fatty acids-derived oxidation products and bisretinoids as potential inducers of CNS diseases: Focus on age-related macular degeneration. Pharmacol Rep. 2013;65(2):288-304.

32. Halliwell B, Gutteridge J. Free Radicals in Biology and Medicine. $3^{\text {rd }}$ ed. Oxford, UK: Oxford University Press; 1999.

33. Starke RM, Chalouhi N, Ali MS, et al. The role of oxidative stress in cerebral aneurysm formation and rupture. Curr Neurovasc Res. 2013;10(3):247-255.

34. Juvela S, Poussa K, Porras M. Natural history of unruptured intracranial aneurysms: Probability of and risk factors for aneurysm rupture. J Neurosurg. 2000;93(3):379-387.

35. Dimitrov JD, Vassilev TL, Andre S, et al. Functional variability of antibodies upon oxidative processes. Autoimmun Rev. 2008;7:574-578.

36. Nielsen MJ, Moestrup SK. Receptor targeting of hemoglobin mediated by the haptoglobins: Roles beyond heme scavenging. Blood. 2009;114(4):764-771.

37. Naraoka M, Matsuda N, Shimamura N, Asano K, Ohkuma H. The role of arterioles and the microcirculation in the development of vasospasm after aneurysmal SAH. Biomed Res Int. 2014;2014:253746.

38. Yu-Ping H, Chih-Lung L, An-Li S, et al. Correlation of $\mathrm{F}_{4}$-neuroprostanes levels in cerebrospinal fluid with outcome of aneurysmal subarachnoid hemorrhage in humans. Free Radic Biol Med. 2009;47(6):814-824. 